\title{
Psychosocial adjustment of Israeli veterans with disabilities: Does employment status matter?
}

\author{
Tal Araten-Bergman ${ }^{\mathrm{a}, *}$, Patricia Tal-Katz ${ }^{\mathrm{b}}$ and Michael Ashley Stein ${ }^{\mathrm{c}, \mathrm{d}, \mathrm{e}}$ \\ ${ }^{a}$ School of Social Work, Social Welfare \& Health Sciences, University of Haifa, Haifa, Israel \\ ${ }^{\mathrm{b}}$ School of Social Work, Ariel University Center of Samaria, Israel \\ ${ }^{\mathrm{c}}$ Executive Director, Harvard Law School Project on Disability, Cambridge, MA, USA \\ ${ }^{\mathrm{d}}$ Harvard Law School, Cambridge, MA, USA \\ ${ }^{\mathrm{e}}$ William \& Mary Law School, Williamsburg, VA, USA
}

Received 15 March 2013

Accepted 18 January 2014

\begin{abstract}
.
BACKGROUND: Since its establishment in 1948, the state of Israel has been deeply committed to reintegrating veterans with disabilities into mainstream society. Prominently, the Israeli Ministry of Defence's rehabilitation division provides veterans with disabilities with a wide array of benefits and services aimed at restoring their physical and psychosocial functioning, especially in the workplace. The focus on employment is motivated by a prevailing assumption among professionals that successful adjustment to disability is contingent on an individual's ability to reacquire normative occupational function. To date, however, this widely accepted wisdom has not been empirically scrutinized.
\end{abstract}

OBJECTIVE: To empirically explore whether employment status is associated to psychological, social, and behavioural adjustment attributes.

METHODS: One hundred and one employed veterans were compared to 111 non-employed veterans in respect to their selfreported levels of hope, acceptance of disability, social networks size and social participation patterns.

RESULTS: Employed veterans reported significantly higher levels psychological adjustment as manifested in elevated hope and acceptance of disability and lighter social network than their non-employed counterparts. However no differences were found between employed and non-employed veterans with respect to their social participation patterns.

CONCLUSIONS: The value of these findings, as well as wider implications for rehabilitation professionals and policy makers, is discussed.

Keywords: Hope, acceptance of disability, social integration

\section{Introduction}

Since its establishment in 1948, the State of Israel has been deeply committed to reintegrating veterans with disabilities into mainstream society, a pledge

${ }^{*}$ Corresponding author: Tal Araten-Bergman, School of Social Work, Social Welfare \& Health Sciences, University of Haifa, Mount Carmel, Haifa 31905, Israel. Tel.: +972 54 4903658; E-mail: talaraten@gmail.com. manifested in its comprehensive disability policy arising from 1949 Invalids' Law [1], which continues to allocate benefits and rehabilitation. The law provides veterans experiencing diminished physical or mental capacity due to their military services with pensions that are not means-tested and an array of state rehabilitation services. The responsibility for managing and implementing the disability veterans program was assigned to the rehabilitation division of the Ministry of Defense (MOD). Israeli government and public obliga- 
tions to the welfare of wounded Israel Defense Force (IDF) veterans is evident in the scope of resources allocated. In 2009, for instance, rehabilitation division funds made up $19 \%$ of the total IDF budget. Furthermore, longitudinal data suggest that these distributions were not affected even in times of economic recession and governmental cutbacks [2].

The MOD's rehabilitation division is accountable for a wide range of comprehensive rehabilitation services designed to assist individuals with disabilities in developing coping skills and motivation necessary for successful psychosocial adjustment and reintegration into mainstream society. MOD [2] data reveal that its rehabilitation division is currently serving 99,000 Israeli veterans with disabilities. Most are entitled to permanent disability pensions (based on the degree of their medically defined disability) as well as a wide range of psychosocial rehabilitation interventions. Services include state-of-the-art medical care, rehabilitation counseling, psychological interventions, vocational skill development, and vocational placement and support.

Analysis of the MOD division's resource distribution reveals a strong orientation toward vocational rehabilitation. Over half of the funds allocated for rehabilitation services are invested in interventions aimed to develop and restore the veterans' ability for gainful employment [2]. This focus on employment as the desired rehabilitation process outcome is based on a $19^{\text {th }}$ century "moral therapy" notion in which work, as a structured activity, was believed to carry therapeutic value $[3,4]$. It is also believed that not working may have devastating personal consequences going beyond one's individual financial situation, such as depression, self-absorption and feelings of worthlessness [5,6]. Indeed, veterans who obtain and retain suitable employment are considered to be rehabilitated and usually cease to utilize the rehabilitation division services. To date, however, this prevailing assumption is not supported by significant empirical data. Therefore it is not clear whether positioning veterans with disabilities in vocational settings facilitate better social inclusion and psychosocial adjustment to acquired disabilities.

In this context, the current study empirically explored the practical assumption that active engagement in the workforce is associated with better psychological adjustment and social integration among Israeli veterans with disabilities. Utilizing a cohort design we compared employed and non-employed veterans with disabilities self-reported levels on a range of wellestablished parameters of rehabilitation outcomes. Our findings may facilitate a deeper understanding of the unique needs of veterans with disabilities as well as contribute to the development of evidence-based practice.

\section{Literature review}

\subsection{Rehabilitation process outcome for veterans with disabilities}

The majority of individuals who acquire a disability or chronic disease during their military service are young males between the ages of 18-30, and were in the early stages of establishing their independence in areas such as friendships, leisure activities, intimate relationships, residence, and employment. There is ample empirical evidence that many personal, environmental, and social factors interact to create a profound effect on these veterans' lives, with the most commonly recognized factors including: the degree of functional limitation, interference with the ability to perform daily activities and life roles, stress associated with incurred trauma or disease itself, impact on family and friends, and sustained financial losses.

Current Israeli veteran disability policy is guided by the notion that coping and adjusting to acquired disabilities requires a complex interaction between the individual and the environment [7]. This view is philosophically aligned with the structural values of the World Health Organization's International Classification of Functioning, Disability, and Health (ICF), which espouses the measurement of individual psychological and social functioning and well-being regardless of the scope or type of impairment [8]. This implies a multidimensional perception of the rehabilitation process, involving interventions targeting medical, psychological, and social aspects of the veterans and their environments. Therefore, evaluation of rehabilitation services outcomes ought to include parameters of health status, psychological well-being, and social integration [9-11]. While it is evident that the medical aspects of the rehabilitation process have clear parameters, understanding, enhancing and evaluating the process of psychological adjustment to acquired disabilities and reintegration continues to pose considerable challenges to rehabilitation professionals.

\subsection{Psychosocial adjustment to disability}

The concept of psychosocial adjustment to disability is fraught with conceptual disagreements, clinically opposed views, and differing research method- 
ologies. For the purpose of this paper we conceptualized psychosocial adjustment as an outcome of an evolving, dynamic, general process through which an individual gradually approaches an optimal state of person-environment congruence as manifested in terms like: 1) reaching and maintaining psychological equilibrium, 2) achieving a state of societal reintegration and social participation, 3) positively striving to reach life goals, 4) demonstrating positive self-esteem, 5) experiencing positive attitudes towards one's self, and 6) acquiring a realistic perception of one's selfincorporating strengths and existing functional limitations [7]. Hence, effective evaluation of psychosocial adjustment to disability as an outcome measure of rehabilitation processes should incorporate cognitive psychological functional and behavioral parameters $[12,13]$. The following discussion provides an overview of common psychological and social indicators of adjustment as rehabilitation outcome measures.

\subsection{Psychological parameters}

\subsubsection{Acceptance of disability}

Acceptance of disability reflects an individual's psychological flexibility and ability to adopt a realistic perspective on strengths and limitations. The term reflects an individual's capability to acknowledge the internal and external effects of their disability on life situations without engaging in dysfunctional mechanisms, and to actively pursue meaningful goals and aspirations [14]. Further, according to Linkowski [15] and Wright [16], the individual level of acceptance is determined by the degree in which the individual is able to: (a) recognize values other than those that are in direct conflict with disability, (b) deemphasize those aspects of ability and appearance that contradict his or her disabling condition, (c) limit the effect of his or her handicap beyond actual impairment to other aspects of the functioning self, and (d) emphasize his or her own assets and abilities rather than compare one's limitations with that of others [16-18].

Acceptance of disability is considered to be a major factor in successful rehabilitation [19]. For example, researchers have found high acceptance of disability to be an important factor in the adjustment of physically disabled persons to their environments [20,21]. Higher levels of disability acceptance were also associated with diminished feelings of distress and better quality of life [21].

\subsubsection{Sense of hope}

Hope is a basic, fundamental, and integral part ofpsychological functioning and mental health, yet in the academic world there is much ambiguity regarding the conceptualization of this term. Varied definitions ranging from wishful thinking to sophisticated well-developed theoretical constructs are being used in the literature [22]. Among them Snyder, Rand and Sigmon's [23,24] cognitive-motivational model of hope stands out since it offers a conceptual framework for the role of hope in adjustment to long lasting disability [25-27]. According to their model, hope is viewed as "the individual's overall perception that one's goals can be met." Hope is theorized to consist of three main components: goal, agency and pathway. The goals must be perceived to be attainable but may also contain a component of uncertainty. Agency is the extent to which an individual believes in his or her capacity to implement action to achieve desired goal, and pathway is defined as individual confidence in the ability to find a way to reach a desired goal and formulate at least one practical means to achieve it $[24,26]$. Agency and pathway are thought to interact to provide a positive motivational state. It is suggested that pathway is particularly important when there are obstacles to the goal. In cases where all pathways are unsuccessful, the development of alternative routes becomes imperative. Research indicates that individuals with high levels of hope believe that they are capable of finding alternative ways to fulfill their desires and usually show more persistence and creativity in their efforts to deliver [24].

Hope has been identified as being potentially important in helping individuals to persevere despite considerable challenges and threats [28-30]. For example, hope has been associated with better rehabilitation outcomes among adults living with fibromyalgia [31] and for adolescent burn survivors [32]. Additionally, higher hope levels have been associated with less depression and psychosocial impairment among individuals with schizophrenia [33].

\subsection{Social parameters}

\subsubsection{Social support}

Rehabilitation is grounded in an ecological model, where the interaction between the individual and environment is critical for adjustment [34]. Therefore it is not surprising that professionals identified social networks and perceived social support as a significant element of psychosocial adjustment and successful reintegration. The concept of social support has been defined as "the social, emotional and instrumental exchanges with which the individual is involved" and "the subjective consequence that an individual sees him or her- 
self as an object of continuing value in the eyes of significant others" [34,35]. Lazarus and Folkman further elaborated on the definition of social support as "a resource available in the social environment, but which the person must cultivate and use" [36, p. 250]. This construction emphasizes the individual's own subjective experience of the supportive nature of social interactions effectiveness.

Three main types of effective social support has been described: emotional, informational, and instrumental [37-39]. Emotional support involves verbal and nonverbal communication of caring and concern and is believed to reduce distress by restoring self-esteem and permitting expression of feelings. Informational support, which involves the provision of information used to guide or advise, is believed to enhance perceptions of control by reducing confusion and providing veterans with disabilities with strategies to cope with their difficulties. Instrumental support involves the provision of material goods (e.g., transportation, financial aid or physical assistance) and may also help decrease feelings of loss of control. Generally it has been thought that the quality, rather than the quantity of social support, appears to buffer individuals against psychological distress [40,41].

Much knowledge exists about the way in which social support influences long-term psychosocial adjustment to disability [42,43]. Research findings suggest that social networks and support can have positive effects on mental health, both directly by increasing self-esteem and indirectly by buffering individuals against the deleterious impact of exposure to stress and trauma [44]. For example, in a recent study, Müller, Cieza and Geyh [45] reviewed 58 publications regarding social support among individuals with mental impairment; their findings indicated a significant positive association between social support and physical and mental health, adjustment and acceptance of disability.

\subsection{Behavioral parameters}

\subsubsection{Social participation patterns}

Social inclusion is an explicit goal of legislation, policies, and support for veterans with disabilities. Successful integration can be defined as being an active and contributing member of one's social groups and society as a whole. The measurement of activities at the personal level assesses the degree to which people with disabilities can participate regularly in social and cultural activities in the community. Research suggests that participating in social and community activi- ties is perceived by consumers to be the most meaningful outcome of the rehabilitation process. Therefore, it is not surprising that individuals reporting higher involvement in social and community activities also demonstrate better psychological adjustment and were generally more satisfied with different aspects of their lives.

\subsection{Employment and psychosocial adjustment to disability}

During the last 60 years Israeli veterans with disabilities programs have held gainful employment as the "gold standard" of rehabilitation interventions. The underlying assumption has been that "work is a pathway to adjustment" [46]. In other words, it has been argued that participation in the labor market results not only in increased income and prevention of poverty, but also assists the population of veterans with disabilities to overcome detrimental psychological effects, social exclusion, and discrimination that may accompany disability. As Blustein [4] notes, "working is a central ingredient in the development and sustenance of psychological health" (p. 230). Further, scholars have argued that labor market participation can lead to the development of social and civic skills that facilitate participation in a variety of community and political activities outside the workplace.

Empirical exploration of the association between employment status and adjustment has yielded mixed findings: some demonstrate non-vocational benefits associated with employment $[47,48]$, but others do not [49-51]. Notably, gainful employment has been shown to affect individuals with traumatic brain injury positively in terms of psychological adjustment to acquired disabilities, as manifested in higher levels of disability acceptance [52,53] and life satisfaction [54]. Employment has also been associated with social and behavioural parameters of adjustment, such as community integration and social networking. Paugam and Russell [55] demonstrated that unemployed individuals are less likely than others to engage in civic groups and other types of community action. Similarly, in a study focusing on individuals with traumatic brain injury, Winkler and colleagues (2006) found that employed individuals reported higher levels of community integration and maintained a wider network of friends and family compared to their unemployed peer cohort [56]. O'Neill et al. [57] (1998) also reported that in their sample of individuals with traumatic brain injury, employment status was strongly re- 
lated to perceived quality of life and level of involvement in home and leisure activities. Roy, Dimigen and Taylor [58] studied the social networks and employment of visually-impaired college graduates and found that those who were employed had a larger social network, were more likely to spend time socially outside of home in bars, social clubs, or informally with friends, and did so more frequently than the unemployed.

However, not all studies have found a positive association between work and psychosocial adjustment. For instance, a prominent study conducted by McHugo and colleagues [59] compared workers and nonworking individuals with mental impairments on a range of objective and subjective non-vocational outcomes over 10 years. Their findings did not find differences in functional and psychosocial adjustment indicators (such as independent living, psychiatric symptoms, substance use disorder, social relationships, and life satisfaction) between the two groups. Likewise Lehman [50] surveyed a group of 496 individuals with severe mental illness and found that employment status was not significantly associated with general life satisfaction, also, hours worked per week was not significantly associated with quality of life.

Although there is a clear conceptual link between employment and psychosocial adjustment to disability, to date research on the association has been scarce and fragmented. Many scholars have focused their attention on one type of disability (for instance, traumatic brain injury, schizophrenia, post-traumatic stress disorder), others have examined sole indicator of adjustment (e.g., social integration or parameter of psychological adjustment) and finally, most studies have focused on short-term adjustment post injury.

Our study explores the association between employment status and psychosocial adjustment in a more integrative perception. By utilizing a cohort design we explore the association between employment status and adjustment indicators encompassing psychological social and behavioural attributes. In addition, by interviewing veterans with disabilities we explore a wide variety of disabilities (physical, sensory and psychiatric), severities, and duration.

\section{Method}

\subsection{Participants and procedures}

Participants were recruited from a list of all veterans receiving services from MOD's rehabilitation di- vision in the northern district of Israel in 2010. Inclusion criteria were defined as working-age males between the ages of 20-60 who have acquired their disability at least three years ago and were recognized by the medical board of the ministry of defence as having a medical permanent disability degree of at least $20 \%$. Data collection was carried out between January 2010 and July 2010, the researchers contacted all 397 potential participants that fit the criteria and asked for their involvement. After obtaining a participant's informed consent, trained researchers administered the questionnaire in the location preferred by the participant, usually home or office. Approval of the data collection protocol was obtained from the Faculty of Health and Social Welfare, University of Haifa, Institutional Review Board.

The final sample that completed the survey consists of 212 Israeli veterans with disabilities. Tables 1 and 2 illustrate their demographic and health characteristics. The data shows that most of the participants were young men with a mean age of 32 years (SD 9.54), with a medical disability degree ranging from $20 \%$ to $100 \%$. Just over half were married (52.8\%) and nearly all participants $(99.1 \%)$ had at least 12 years of education. $31.1 \%$ of the sample had tertiary education. The participants had acquired their disability 6-12 years ago $(\mathrm{M}=6.15$, SD 6.31). Most participants (80.7\%) reported having a physical impairment; about one-third reported having a mental impairment (mainly posttraumatic stress disorder). Most (63.3\%) participants perceived their disabilities as moderate to severe, $3.8 \%$ viewed their disability as very slight, and $15.1 \%$ ranked their disability as very severe.

\subsection{Measures}

\subsubsection{Psychological parameters}

The survey questionnaire was comprised of the following instruments:

1) Acceptance of Disability Scale (ADS) [15] comprised of 50 self-reported items. Each item has a 6-point Likert scale with response categories ranging from strongly disagree (1) to strongly agree (6). An overall acceptance of disability score is derived by summing all items, with 300 as the highest possible score. Low acceptance scores fall below 175, whereas high acceptance scores range from 176 to 300 [60]. The ADS has been reported to have an internal consistency coefficient of 0.93 with a population of rehabilitation clients. In the current study, the alpha Cronbach for the combined scale was 0.85 . 
Table 1

Demographic and health characteristics by employment status $(n=212)$

\begin{tabular}{|c|c|c|c|c|c|c|}
\hline \multirow[t]{2}{*}{ Variable categories } & \multicolumn{3}{|c|}{ Employed $(n=101)$} & \multicolumn{3}{|c|}{ Non-Employed $(n=111)$} \\
\hline & $\%$ & Mean & SD & $\%$ & Mean & SD \\
\hline Age & & 31.97 & 9.23 & & 30.64 & 9.57 \\
\hline \multicolumn{7}{|l|}{ Marital status } \\
\hline Single & 16.3 & & & 20.2 & & \\
\hline Married/significant other & 66.6 & & & 61.1 & & \\
\hline Separated/divorced & 10.1 & & & 18.7 & & \\
\hline Widowed & 7 & & & - & & \\
\hline \multicolumn{7}{|l|}{ Education } \\
\hline Less than high school graduate & 31.7 & & & 52.3 & & \\
\hline High school graduate & 29.7 & & & 21.6 & & \\
\hline College degree & 37.6 & & & 25.2 & & \\
\hline Graduate school & 15.2 & & & 12.1 & & \\
\hline \multicolumn{7}{|l|}{ Degree of disability (self-reported) } \\
\hline Mild & 13.2 & & & 10.1 & & \\
\hline Moderate & 34.4 & & & 32.3 & & \\
\hline Somewhat severe & 35.3 & & & 29.4 & & \\
\hline Severe & 17.1 & & & 28.2 & & \\
\hline \multicolumn{7}{|l|}{ Type of impairment } \\
\hline Physical impairment & 20.4 & & & 22.3 & & \\
\hline Sensory impairment & 18.7 & & & 17.6 & & \\
\hline \multirow[t]{2}{*}{ Mental impairment } & 39.9 & & & 32.2 & & \\
\hline & 19.3 & & & 11.9 & & \\
\hline
\end{tabular}

Table 2

Pearson and Spearman correlation between adjustment parameters and background characteristics $(n=212)$

\begin{tabular}{lcccccc}
\hline & $\begin{array}{c}\text { Acceptance of } \\
\text { disability }\end{array}$ & $\begin{array}{c}\text { Social } \\
\text { network }\end{array}$ & $\begin{array}{c}\text { Social } \\
\text { participation }\end{array}$ & Employment & $\begin{array}{c}\text { Education } \\
\text { Impairment type } \\
\text { physical/mental }\end{array}$ \\
\hline Hope & $66^{* *}$ & $52^{* *}$ & $0.12^{*}$ & $0.19^{*}$ & $20^{* *}$ & $0.22^{* *}$ \\
Acceptance of disability & & $45^{* *}$ & $0.15^{*}$ & $0.25^{*}$ & $0.27^{*}$ & $0.25^{* *}$ \\
Social network & & $0.42^{* *}$ & $0.25^{*}$ & 0.8 & $0.12^{*}$ \\
Social participation & & & & $18^{* *}$ & 13 & 0.37 \\
Employment & & & & $32^{* *}$ & $0.29^{* *}$ \\
Years of education & & & & $15^{* *}$ & $19^{*}$ \\
\hline
\end{tabular}

$p<0.05^{*}, p<0.01^{* *}$.

2) The Hope Scale (HS) [25] comprised of 12-item Likert-type scale with four items assessing pathways, four items assessing agency, and four distracters. For each item response range from $1=$ definitely false to $4=$ definitely true. The $\mathrm{HS}$ yields separate scores for each element in addition to a total hope score, however in the current study comparative factor analysis did not yield three distinctive factors, therefore we calculated only a total hope score. In the current study, Cronbach alpha for the combined hope scale was 0.89 .

\subsubsection{Social parameters}

3) Social Network Scale (LSNS) [61] originally published as a 10-item scale for examining social isolation. The LSNS-18 utilized in this study was developed to increase reliability and to accommodate research in the field of social and health science [62]. The tool is comprised of 18 items representing three social systems: family, friends and neighbours. For each the LSNS assesses the size of social networks and frequency of contact. Responses are rated on Likert-type scale ranging from 1 to 5 . Overall score is computed by summing response to the 18 items. Lower scores indicate smaller networks [63]. The authors report Cronbach's alpha of 0.82 [62]. In the current study Cronbach's alpha was found to be 0.90 .

\subsubsection{Behavioural parameters}

4) Social participation patterns were assessed with the Activity Pattern Indicators [64]. Participants were provided with a list of 20 social activities (such as dining out, participating in cultural events, going to movies, theater concerts and shows, and hosting and visiting friends) and were asked to report how many hours a week they 
spent engaged in these activities. The score was calculated by summing up all hours spent on activities. Higher scores indicate greater participation patterns.

\subsubsection{Control variables}

5) Socio-demographic characteristics included items relating to the participant age, race and ethnicity, religion, religiosity, marital status (single, living with a spouse, married, divorced, widowed) years of education and highest degree completed by the participant (less than high school graduate; high school graduate; College degree, Graduate school).

6) Health characteristics included items relating to the participant type of disability (physical, sensory, mental, learning disabilities, comorbidity); duration of disability (time passed since injury); degree of disability (\% medical disability) and subjective perception of disability (slight, moderate, severe, very severe).

7) Employment included items relating to the participant employment status (employed/not employed); employment setting (supported employment, gainful employment, sheltered employment); employment scope (number of hours worked per week) and the length of time the participant work.

\subsection{Statistical analysis}

All statistical analysis was performed using SPSS for Windows version 19, and included the following steps: first, in order to test the construct of psychosocial adjustment we conducted a set of Pearson correlation analysis between social, psychological and behavioral parameters of psychosocial adjustment. Then, to detect control variables we tested the correlation between psychosocial adjustment variables and veterans background characteristics, using Pearson correlation and a cross-tabulated chi-square analysis for categorical demographic variables. Next, we compared employed and non-employed participants on demographic and health characteristics using chi-square and t-test analysis to establish group differences and control variables. Finally, we compared employed and non-employed participants mean scores on the different domains of psychosocial adjustment parameters. Differences between groups were determined by an independent samples t-test.

\section{Results}

In the present study participants were categorized as employed if they reported engaging in vocational activities (not less than 15 hours per week) for at least 60 days prior to the survey administration. Participants who reported they did not hold a paid job and had not actively sought work in the last two months were considered labor force non-participants $(n=111)$. Finally, participants who reported looking for a job, or working less than 15 hours a week were excluded from the statistical analysis $(n=19)$. Post hoc analysis conducted within the employed group sample did not yield any significant differences between individuals employed in competitive settings and individuals working in sheltered settings. Likewise, no significant differences were found with regard to any of the employment characteristics. Therefore, further analysis of the employed sample was not stratified by type of employment, setting or scope (working hours).

Next, in order to test our research questions regarding the association between employment and adjustment we had to establish first whether the employed and non-employed groups demographic and health characteristics significantly differ, the results are presented in Table 3. Employed and non-employed participants did not differ significantly on background characteristics (such as age, marital status, ethnicity, religion and religiosity). The most frequently reported types of impairment in both groups were physical $39.9 \%$ of the employed and $32.2 \%$ of the nonemployed), and sensory (39.1\% of the employed sample and $39.9 \%$ of the non-employed). The employed sample reported slightly more education, $67.3 \%$ of the employed had post-high school education compared to $46.8 \%$ of the non-employed.

Significant differences were also obtained for disability severity, with the employed individuals perceived their disabilities as less severe than those in the non-employed ( $t=4.01, p<0.05$ ). The nonemployed sample consisted of significantly more individuals with self-reported mental impairment, mostly post-traumatic stress disorder (PTSD). Based on these finding, in all further statistical analyses years of education, type of disability and disability severity served as covariates.

Then, in order to test the construct of psychosocial adjustment we conducted a set of Pearson correlation analysis between social psychological and behavioral parameters of psychosocial adjustment as well as personal characteristics. Table 3 presents the correlation 
Table 3

Means, standard deviation, $\mathrm{t}$ values of hope, acceptance of disability, social network and social participation by employment status $(n=212)$

\begin{tabular}{|c|c|c|c|c|c|}
\hline & \multicolumn{2}{|c|}{ Employed $(n=101)$} & \multicolumn{2}{|c|}{ Non-employed $(n=111)$} & \multirow[t]{2}{*}{$\mathrm{t}$} \\
\hline & $\mathrm{M}$ & SD & $\mathrm{M}$ & SD & \\
\hline Acceptance of disability & 200.25 & 46.08 & 167.27 & 47.84 & $5.10^{* *}$ \\
\hline Hope & 24.87 & 4.43 & 22.49 & 5.57 & $3.41^{* *}$ \\
\hline Social network & 46.36 & 13.44 & 38.02 & 16.82 & $4.00^{* *}$ \\
\hline Social participation & 28.02 & 21.69 & 34.50 & 35.55 & 1.134(ns) \\
\hline
\end{tabular}

$p<0.05^{*}, p<0.01^{* *}$.

matrix between the research variables and background characteristics.

A strong and significant correlation was found between the psychological and social parameters of adjustment, yet only a modest but significant correlation was detected between behavioral patterns of social participation and hope, $(r=0.12 p<0.05)$ and acceptance of disability $(r=13 p<0.05)$. In addition, a positive correlation was also found between the background characteristics of the participants and psychosocial adjustment. Therefore, all further analysis was controlled for education and disability type.

\subsection{Employment and psychosocial adjustment}

Descriptive statistics and independent sample t-test were used to compare employed and non-employed participants mean scores on psychological (sense of hope and acceptance of disability), social (perception of social support) and behavioral indicators (social participation) of adjustment to acquired disabilities. Years of education, type of disability (physical vs. mental impairment) and degree of medical disability served as covariates (see Table 3). Employed and non-employed participants showed significant differences in the psychosocial indicators of adjustment, however no differences were found between the groups in regards to behavioral indicators. Specifically, employed participants demonstrated significantly higher levels of disability acceptance $(t=5.10, p<0.01)$, as well as a greater sense of hope $(t=3.41, p<0.01)$. They also showed wider social networks $(t=4.00, p<0.01)$. However, no significant differences were found between the groups in regards to their social participation patterns. In fact employed participants, regardless of the scope of work, reported spending less time in social and recreational activities outside the workplace.

\section{Discussion}

The main goal of the Israeli program for veterans with disabilities has been to provide this population with adequate services and resources for successful psychosocial adjustment, and to promote their social and civic reintegration. However, disability rights advocates and rehabilitation professionals have recognized the need to utilize valid, relevant, and reliable measures to assess the efficacy of this program. The findings presented here may serve as a preliminary step in this direction and contribute to better clinical and practical evaluation of rehabilitation practice in both individual and policy levels of analysis.

First, our findings support the notion that adjustment to disability is a multidimensional construct that encompasses psychological, social, interpersonal and behavioral distinct yet related domains. For instance, our findings demonstrate that overall psychosocial parameters of adjustment do not necessarily manifest themselves in behavioral patterns. Specifically although there was a strong association between acceptance of disability, sense of hope, and the size of the social network, these attributes did not necessarily contribute to higher levels of community participation and social integration. This finding empirically supports the philosophical values of the social model of disability, which suggests that a host of personal, social, and environmental factors may interact and create a complex series of adjustment milestones, which could uniquely affect the individual's identity, self-perception and social functioning. In alliance with this view, our findings demonstrate the importance of relying on multiple outcome parameters when assessing the value of rehabilitation intervention or policies. Hence, it seems that in order to provide a more comprehensive view of rehabilitation efficacy, evaluation efforts should address specifically psychological, social and behavioral domains instead of solely relying on specific attribute (such as social integration or psychological adjustment).

Next, findings indicate that employed and nonemployed participants did not differ in most demographic and health characteristics (age, marital status, religion and religiosity). Significant differences found between the groups were that the employed partici- 
pants reported slightly more years of education and that higher employment rates were found among veterans with physical disabilities in comparison to veterans with mental impairment and PTSD.

The lack of association between demographic characteristics and employment status is not surprising since it has been collaborated in earlier research [6567]. Also the low employment rates of veterans with mental illness is consistent with recent findings in the international arena documenting similar gaps in labour market participation [68-70]. An examination of the effectiveness of vocational rehabilitation programs carried out in various countries around the western world (mainly the US, Australia and UK) revealed that these programs are not aligned with the unique needs of veterans with PTSD [71,72]. Further, empirical and clinical findings expose that the population of veterans with post-traumatic stress disorder do not receive appropriate, tailored responses within universal vocational rehabilitation services [73]. Therefore, it is important that professionals consider the unique nature of each disability when designing programs that can provide a genuine response to specific needs to promote the adequate adjustment.

The primary focus of the current study was to empirically examine the association between employment status and psychosocial adjustment. Core findings suggest that employed individuals report higher levels of hope and acceptance of disability and have larger social networks then their non-employed counterparts. These associations were found to be stable even after controlling for most demographic and health characteristics.

The association between employment status and the veteran psychological adjustment to acquired disability may be explained by the latent deprivation model developed by Jahoda [74]. According to this model, employment not only provides the individual with financial resources but also with latent benefits. These include: (i) imposing a time structure; (ii) providing regularly shared experiences and social contacts; (iii) providing links to goals and purposes that transcend the person's own circumstances; (iv) giving a definition of personal status and identity, and v) enforcing activity. Jahoda's theory further postulates that psychological and social functions are rooted in the productive activity of work itself, and are not dependent on the type, scope or level of job satisfaction [74]. Although our study is cross-sectional and does not allow to establish causality, in accordance with Jahoda's theory it may suggest that being employed may lead to better psy- chological functioning. Employment may assist individuals to adjust their values system in a manner that mitigates negative self-perceptions as able and competent arising from actual or perceived losses from disability. Hence, employment may contribute to veterans with disabilities' level of acceptance of their disability; moreover, active engagement in employment facilitates a continuation of a "normative" life course and fulfillment of valid social roles. This may result in increased self-esteem and sense of competence, mastery and hope, allowing the individual to reinterpret selfidentity to incorporate a more positive self-image and break away from stigmatizing acculturated identity as disabled, leading to enhanced psychological growth.

Employment may also lead to increased social networks since veterans with disabilities are offered an opportunity to develop and utilize social skills as well as forge friendships with others in the workplace. The association between employment and social network can be further explained by the quality of relations with family and friends. Empirical findings suggest that employment is considered a key indicator of functioning and acceptance of the individual with disabilities among nondisabled peers [75-78]. In the context of employment, existing social ties can be normalized in the sense that employed veteran may be perceived by significant others as competent to fill a desirable social role (such as provider) and maintain a common life style despite physical or mental impairment.

However, it is interesting to note that despite significant differences between employed and non-employed veterans regarding the size of their respective social networks, these differences did not translate into higher levels of social and community integration. This finding was somewhat surprising given the clinical assumption that work is a pathway to social integration [79]. It seems that the relationship between employment status and social participation is more complex and affected by factors that are beyond the scope of the present study. For instance, previous research has demonstrated that the physical environment in which the veterans conduct their lives are likely to facilitate or hinder social participation patterns [80]. For example, in a large sample of 2,726 individuals with spinal cord injuries, Whiteneck and his colleagues [81] found that approximately $80 \%$ reported that environmental barriers interfered with their ability to participate fully in society. Although our findings do not address the specific objective environmental conditions the veterans face, the lack of association between psychosocial adjustment and behavioral outcomes sug- 
gests that psychological adjustment to an acquired disability may not mediate the direct relation between social participation and environmental factors. Hence, even in light of positive self-perception, self-esteem, social skills and social networks, veterans with disabilities may not be able to realize their human rights for full and equal participation in all spheres of community life.

\subsection{Limitations}

There are some notable limitations to this study. Primarily, research methods and design relying on selfreported measures: there is substantial controversy in the literature over the validity of self-reported health and disability indicators as explanatory variables [8285]. Some scholars claim they are biased and endogenous, others support the use of subjective disability indicators based on research findings suggesting only marginal increases in explanatory power from using additional more objective indicators. Although our study contrasted subjective self-reports with objectives indicators of health and disability as controls, we accept the notion that disability is a subjective and socially determined concept. Second, the employment measure was also self-reported and covered a 60-day time period. Because any given person's employment status can fluctuate, this measure did not capture a more longitudinal picture. Third, analyses were not stratified by employment setting, type or scope. The modest sample size of employed veterans restricted the statistical power to analyse and control employment settings and hours worked, increasing the likelihood of type II error, therefore it is possible that the lack of significant statistical differences within the employed sample stems from the small number of participants in each group. A final limitation of this study concerns the research design. Our findings rely on crosssectional and correlation analyses, which limits the extent to establish causality between employment status, psychosocial adjustment and social participation. Further, panel studies are needed to increase our knowledge of the importance of reciprocal relationships by disentangling and clarifying how exogenous and endogenous factors relate to the association between employment, psychosocial adjustment and participation in economic and community activities.

\subsection{Conclusion}

The present findings provide a snapshot of the Israeli population of veterans with disabilities, facilitat- ing a broad empirical exploration of psychosocial adjustment across different disability group and allowing for variance in socio-demographic and health characteristics (i.e. disability type, time since disability occurrence, severity, years of age, etc.).

Our analysis illustrated the importance of assessing psychosocial adjustment as a multidimensional construct. Clearly, a better conceptualization of rehabilitation interventions outcome is critical to improve care, inform public policy, and guide legislative efforts. It may also assist professionals in defining the nature of their responsibilities, to set interventions and to assess the effectiveness of these interventions in valid and reliable ways. Therefore, future studies need to focus on the development of a conceptual framework for understanding the many aspects of psychosocial adjustment to acquired disabilities, and equally important, come to consensus on the indicators that can be used to measure those aspects.

Second, the evidence presented illustrates the importance of psychological parameters of the adjustment process. It seems that veterans' subjective appraisal of their disabilities, their perceived control on their environments, and their understanding of long-term outcomes will determine their motivation as well as their personal and social resources for the rehabilitation process. The theoretical understanding of hope and acceptance of disability presented can inspire professionals to develop more effective interventions targeted at psychological growth. For instance, interventions aimed at exploring veterans' meanings and appraisals, to supporting the development of problem-solving skills, to providing veterans with knowledge and confidence to self-manage their disabilities, and toward empowering them to form realistic goals, enlist motivation and facilitate the planning of productive outcomes. Also, behavioural interventions that assist the development of self-efficacy, and encourage reengagement in social relationships and social or recreational activities may prove useful in promoting the psychosocial adjustment and reintegration of veterans with disabilities. On a parallel track, it is important to address environmental and attitudinal barriers. Veterans with disabilities are confronted with many barriers and limitations imposed by social, political, and cultural systems. Hence, macro interventions targeted at removing systemic barriers are essential.

Third, our findings indicate the existence of interaction between employment status and different aspects of psychosocial functioning for veterans with disabilities. Further research is needed to empirically explore 
the unique contribution of employment on the different dimensions of psychosocial adjustment.

Finally, a comprehensive synthesis of research findings from a range of perspectives is necessary if we are to develop an adequate understanding of the adjustment outcome following a combat-related disability. To our view this integrated understanding is essential to developing an adequate response to support positive adjustment across multiple life domains.

\section{References}

[1] Israeli Invalids Law: Benefits and Rehabilitation, 5719-1959 (Consolidated version).

[2] Ministry of Defense report for 2009 (Freedom of Information Law). Israeli Ministry of Defense, 2009.

[3] Anthony WA, Liberman RP. The practice of psychiatric rehabilitation: historical, conceptual, and research base. Schizophr Bull. 1986; 12(4): 542.

[4] Blustein DL. The role of work in psychological health and well-being: A conceptual, historical, and public policy perspective. Am Psychol. 2008; 63(4): 228.

[5] Marrone J, Golowka E. If work makes people with mental illness sick, what do unemployment, poverty, and social isolation cause? Psychiatr Rehabil J. 1999; 23(2): 187-93.

[6] Lysaght R, Cobigo V, Hamilton K. Inclusion as a focus of employment-related research in intellectual disability from 2000 to 2010: A scoping review. Disabil Rehabil. 2012 Jan; 34(16): 1339-50.

[7] Antonak RF, Livneh H. Psychosocial adaptation to disability and its investigation among persons with multiple sclerosis. Soc Sci Med. 1995 Apr; 40(8): 1099-108.

[8] CAD P. International classification of functioning, disability and health (ICF). 2001;

[9] Rosenbaum P, Stewart D. The World Health Organization International Classification of Functioning, Disability, and Health: A model to guide clinical thinking, practice and research in the field of cerebral palsy. Seminars in Pediatric Neurology. Elsevier, 2004, pp. 5-10.

[10] Altshuler L, Tekell J, Biswas K, Kilbourne AM, Evans D, Tang D, et al. Executive Function and Employment Status Among Veterans With Bipolar Disorder. Psychiatr Serv. 2007 Nov 1; 58(11): 1441-7.

[11] Powers LE, Sowers J-A, Singer GHS. A Cross-Disability Analysis of Person-Directed, Long-Term Services. J Disabil Policy Stud. 2006 Sep 1; 17(2): 66-76.

[12] Livneh H. Psychosocial Adaptation to Chronic Illness and Disability A Conceptual Framework. Rehabil Couns Bull. 2001 Apr 1; 44(3): 151-60.

[13] Chevalier Z, Kennedy P, Sherlock O. Spinal cord injury, coping and psychological adjustment: A literature review. Spinal Cord. 2009 Nov; 47(11): 778-82.

[14] Heinemann AW, Shontz FC. Acceptance of disability, selfesteem, sex role identity, and reading aptitude in deaf adolescents. Rehabil Couns Bull. 1982; 25: 197-203.

[15] Linkowski DC. A scale to measure acceptance of disability. Rehabil Couns Bull. 1971; 14(4): 236-44.

[16] Wright BA. Developing constructive views of life with a disability, 1983.
[17] Dembo T, Leviton GL, Wright BA. Adjustment to misfortune: A problem of social-psychological rehabilitation. Rehabil Psychol. 1975; 22(1): 1 .

[18] Berglund B, Mattiasson AC, Nordström G. Acceptance of disability and sense of coherence in individuals with EhlersDanlos syndrome. J Clin Nurs. 2003; 12(5): 770-7.

[19] Anderson D. Determinants of return to work among spinal cord injury patients: a literature review. J Vocat Rehabil. 2007; 27(1): 57.

[20] Elliott TR, Uswatte G, Lewis L, Palmatier A. Goal instability and adjustment to physical disability. J Couns Psychol. 2000; 47(2): 251 .

[21] Nicholls E, Lehan T, Plaza SLO, Deng X, Romero JLP, Pizarro JAA, et al. Factors influencing acceptance of disability in individuals with spinal cord injury in Neiva, Colombia, South America. Disabil Rehabil. 2012 Jan; 34(13): 1082-8.

[22] Farran CJ, Herth KA, Popovich JM. Hope and hopelessness: Critical clinical constructs. Thousand Oaks, CA, US: Sage Publications, Inc; 1995, p. 250.

[23] Farran CJ, Herth KA, Popovich JM. Hope and hopelessness: Critical clinical constructs. Sage Publications, Inc, 1995.

[24] Snyder CR. Handbook of hope: Theory, measures, and applications. Academic press, 2000.

[25] Snyder CR, Harris C, Anderson JR, Holleran SA, Irving LM, Sigmon ST, et al. The will and the ways: development and validation of an individual-differences measure of hope. J Pers Soc Psychol. 1991; 60(4): 570.

[26] Snyder CR, Cheavens J, Sympson SC. Hope: An individual motive for social commerce. Group Dyn Theory Res Pract. 1997; 1(2): 107.

[27] Snyder CR. Conceptualizing, measuring, and nurturing hope. J Couns Dev. 1995; 73(3): 355-60.

[28] Buckelew SP, Hanson S. Coping and adjustment following spinal cord injury. SCI Psychosoc Process. 1992; (5): 99-103.

[29] Lohne V. Hope in patients with spinal cord injury: A literature review related to nursing. J Neurosci Nurs J Am Assoc Neurosci Nurses. 2001; 33(6): 317.

[30] Morse JM, Doberneck B. Delineating the concept of hope. J Nurs Scholarsh. 2007; 27(4): 277-85.

[31] Affleck G, Tennen H. Construing benefits from adversity: Adaptational significance and dispositional underpinnings. J Pers. 1996; 64(4): 899-922.

[32] Barnum DD, Snyder CR, Rapoff MA, Mani MM, Thompson $\mathrm{R}$. Hope and social support in psychological adjustment of children who have survived burn injuries and their matched controls. Child Health Care. 1998; 27(1): 15-30.

[33] Lysaker PH, Roe D, Yanos PT. Toward understanding the insight paradox: internalized stigma moderates the association between insight and social functioning, hope, and selfesteem among people with schizophrenia spectrum disorders. Schizophr Bull. 2007; 33(1): 192-9.

[34] Chronister JA, Johnson EK, Berven NL. Measuring social support in rehabilitation. Disabil Rehabil. 2006; 28(2): 75-84.

[35] Williams P, Barclay L, Schmied V. Defining social support in context: A necessary step in improving research, intervention, and practice. Qual Health Res. 2004; 14(7): 942-60.

[36] Lazarus RS, Folkman S. Stress, appraisal, and coping. Springer Publishing Company, 1984.

[37] Antonucci TC. Social support: Theoretical advances, recent findings and pressing issues. Soc Support Theory Res Appl. 1985, 21-37.

[38] House JS, Kahn RL, McLeod JD, Williams D. Measures and concepts of social support, 1985.

[39] Rimmerman A, Araten-Bergman T. Social Participation of 
Employed and Unemployed Israelis With Disabilities. J Soc Work Disabil Rehabil. 2009; 8(3-4): 132-45.

[40] Kennedy P, Rogers BA. Anxiety and depression after spinal cord injury: A longitudinal analysis. Arch Phys Med Rehabil. 2000; 81(7): 932-7.

[41] Kennedy P, Rogers B. Reported quality of life of people with spinal cord injuries: a longitudinal analysis of the first 6 months post-discharge. Spinal Cord. 2000; 38(8): 498.

[42] McCabe MP, McKern S, McDonald E. Coping and psychological adjustment among people with multiple sclerosis. J Psychosom Res. 2004; 56(3): 355-61.

[43] Schwartz C, Frohner R. Contribution of demographic, medical, and social support variables in predicting the mental health dimension of quality of life among people with multiple sclerosis. Health Soc Work. 2005; 30(3): 203-12.

[44] Cohen S, Syme SL. Issues in the study and application of social support. Soc Support Health. 1985; 3: 3-22.

[45] Müller R, Peter C, Cieza A, Geyh S. The role of social support and social skills in people with spinal cord injury - a systematic review of the literature. Spinal Cord. 2011; 50(2): 94-106.

[46] Winkler D, Unsworth C, Sloan S. Factors that lead to successful community integration following severe traumatic brain injury. J Head Trauma Rehabil. 2006; 21(1): 8-21.

[47] Arns PG, Linney JA. Work, self, and life satisfaction for persons with severe and persistent mental disorders. Psychosoc Rehabil J, 1993.

[48] Eklund M, Hansson L, Ahlqvist C. The importance of work as compared to other forms of daily occupations for wellbeing and functioning among persons with long-term mental illness. Community Ment Health J. 2004; 40(5): 465-77.

[49] Fabian ES. Longitudinal outcomes in supported employment: A survival analysis. Rehabil Psychol. 1992; 37(1): 23.

[50] Lehman AF. A quality of life interview for the chronically mentally ill. Eval Program Plann. 1988; 11(1): 51-62.

[51] Dongen CJ. Quality of life and self-esteem in working and nonworking persons with mental illness. Community Ment Health J. 1996; 32(6): 535-48.

[52] Kreuter M, Sullivan M, Dahllöf AG, Siösteen A. Partner relationships, functioning, mood and global quality of life in persons with spinal cord injury and traumatic brain injury. Spinal Cord. 1998; 36(4): 252.

[53] O'Neill J, Hibbard MR, Brown M, Jaffe M, Sliwinski M, Vandergoot D, et al. The effect of employment on quality of life and community integration after traumatic brain injury. J Head Trauma Rehabil. 1998 Aug; 13(4): 68-79.

[54] Corrigan JD, Bogner JA, Mysiw WJ, Clinchot D, Fugate L. Life satisfaction after traumatic brain injury. J Head Trauma Rehabil. 2001; 16(6): 543-55.

[55] Paugam S, Russell $\mathrm{H}$. The effects of employment precarity and unemployment on social isolation. In: Gallie D, Paugam S, editors. Welfare Regimes and the Experience of Unemployment in Europe. Oxford: Oxford University Press, 2000.

[56] Winkler D, Farnworth L, Sloan S, Brown T. Transition of Younger People with Acquired Brain Injury from Residential Aged Care to Community Living: Anticipated and Actual Outcomes. Brain Impair. 2006 May; 7(1): 54.

[57] O'Neill J, Hibbard MR, Brown M, Jaffe M, Sliwinski M, Vandergoot D, et al. The effect of employment on quality of life and community integration after traumatic brain injury. J Head Trauma Rehabil. 1998; 13(4): 68-79.

[58] Roy AWN, Dimigen G, Taylor M. The Relationship between Social Networks and the Employment of Visually Impaired College Graduates. J Vis Impair Blind. 1998; 92(7): 423-32.
[59] McHugo GJ, Drake RE, Xie H, Bond GR. A 10-year study of steady employment and non-vocational outcomes among people with serious mental illness and co-occurring substance use disorders. Schizophr Res, 2012.

[60] Joiner JG, Lovett PS, Goodwin LK. Positive Assertion and Acceptance Among Persons with Disabilities. J Rehabil. 1989.

[61] Lubben JE. Assessing social networks among elderly populations. Fam Community Health J Health Promot Maint Fam Community Health J Health Promot Maint. 1988.

[62] Lubben J, Gironda M. Centrality of social ties to the health and well-being of older adults. Soc Work Health Care Aging Soc. $2003 ; 319-50$

[63] Lubben J, Lee A, Gironda M. Analysis and further development of the Lubben Social Network Scale. ESRC Seminar Series on Social Networks and Social Exclusion, Bangor, MN. 2000.

[64] Diller L, Fordyce W, Jacobs D, Brown M. Activity Pattern Indicators: Self-Administered Inventory. Rehabil Indic Proj NYU Med Cent. 1981.

[65] Anthony WA, Jansen MA. Predicting the vocational capacity of the chronically mentally ill: Research and policy implications. Am Psychol Am Psychol. 1984; 39(5): 537.

[66] Bond GR. Supported employment: evidence for an evidencebased practice. Psychiatr Rehabil J. 2004; 27(4): 345-59.

[67] Mueser KT, Becker DR, Torrey WC, Xie H, Bond GR, Drake $\mathrm{RE}$, et al. Work and nonvocational domains of functioning in persons with severe mental illness: A longitudinal analysis. J Nerv Ment Dis. 1997; 185(7): 419-26.

[68] Christensen E, McMahon J, Schaefer ES, Jaditz T, Harris D. Final Report for the Veterans' Disability Benefits Commission: Compensation, Survey Results, and Selected Topics. CNA Corp Alex VA August. 2007; 1888932-2946.

[69] Smith MW, Schnurr PP, Rosenheck RA. Employment outcomes and PTSD symptom severity. Ment Health Serv Res. 2005; 7(2): 89-101.

[70] Frueh BC, Elhai JD, Gold PB, Monnier J, Magruder KM, Keane TM, et al. Disability compensation seeking among veterans evaluated for posttraumatic stress disorder. Psychiatr Serv. 2003;54(1):84-91.

[71] Rosenheck R, Stolar M, Fontana A. Outcomes monitoring and the testing of new psychiatric treatments: Work therapy in the treatment of chronic post-traumatic stress disorder. Health Serv Res. 2000; 35(1 Pt 1): 133.

[72] Foa EB, Keane TM, Friedman MJ, Cohen JA. Effective treatments for PTSD: practice guidelines from the International Society for Traumatic Stress Studies. The Guilford Press, 2008.

[73] Forbes D, Creamer M, Bisson JI, Cohen JA, Crow BE, Foa $\mathrm{EB}$, et al. A guide to guidelines for the treatment of PTSD and related conditions. J Trauma Stress. 2010; 23(5): 537-52.

[74] Jahoda M. Employment and unemployment: A socialpsychological analysis. Cambridge University Press, 1982.

[75] Argentzell E, Håkansson C, Eklund M. Lund University Publications. Scand J Occup Ther. 2010;

[76] Bengtsson-Tops A, Hansson L. Quantitative and qualitative aspects of the social network in schizophrenic patients living in the community. Relationship to sociodemographic characteristics and clinical factors and subjective quality of life. Int J Soc Psychiatry. 2001; 47(3): 67-77.

[77] Bond GR, Resnick SG, Drake RE, Xie H, McHugo GJ, Bebout RR. Does competitive employment improve nonvocational outcomes for people with severe mental illness? J Consult Clin Psychol J Consult Clin Psychol. 2001; 69(3): 489. 
[78] Riches VC, Green VA. Social integration in the workplace for people with disabilities: An Australian perspective. J Vocat Rehabil. 2003; 19(3): 127-42.

[79] Winkler D, Farnworth L, Sloan S, Brown T. Transition of younger people with acquired brain injury from residential aged care to community living: anticipated and actual outcomes. Brain Impair. 2006; 7(1): 54.

[80] Jette AM, Keysor JJ. Uses of evidence in disability outcomes and effectiveness research. Milbank Q. 2002; 80(2): 325-45.

[81] Whiteneck G, Meade MA, Dijkers M, Tate DG, Bushnik T, Forchheimer MB. Environmental factors and their role in participation and life satisfaction after spinal cord injury. Arch Phys Med Rehabil. 2004; 85(11): 1793-803.
[82] Filmer D. Disability, poverty, and schooling in developing countries: Results from 14 household surveys. World Bank Econ Rev. 2008; 22(1): 141-63.

[83] Kreider B, Pepper JV. Disability and employment: reevaluating the evidence in light of reporting errors. J Am Stat Assoc. 2007; 102(478): 432-41.

[84] Baker M, Stabile M, Deri C. What do self-reported, objective, measures of health measure? J Hum Resour. 2004; 39(4): 1067-93.

[85] Benítez-Silva H, Buchinsky M, Man Chan H, Cheidvasser S, Rust J. How large is the bias in self-reported disability? J Appl Econom. 2004; 19(6): 649-70. 